\title{
Compulsive Social Behavior Emerges after Selective Ablation of Striatal Cholinergic Interneurons
}

\author{
Yanina V. Martos, @Barbara Y. Braz, Juan P. Beccaria, M. Gustavo Murer, and Juan E. Belforte \\ Universidad de Buenos Aires. Facultad de Medicina, Departamento de Fisiología, Buenos Aires, Argentina, and CONICET-Universidad de Buenos Aires, \\ Instituto de Fisiología y Biofísica "Bernardo Houssay" (IFIBIO-Houssay), Grupo de Neurociencia de Sistemas, Buenos Aires 1121, Argentina
}

The mechanisms underlying social dysfunction in neuropsychiatric conditions such as obsessive-compulsive disorder and Tourette syndrome remain uncertain. However, it is known that dysfunctions in basal ganglia, including a reduced number of striatal cholinergic interneurons (SCIN), are involved in their pathophysiology. To explore the role of SCIN in relation to perseverative behaviors, we characterized a new transgenic mouse model in which inducible ablation of SCIN is achieved with high efficiency in a cell-type- and region-specific manner. Mice were subjected to extensive behavioral testing, including assessment of social behaviors, and corticostriatal functional connectivity was evaluated in vivo. Selective SCIN ablation leads to altered social interactions together with exacerbated spontaneously emitted repetitive behaviors. Lesioned mice showed normal motor coordination, balance, and general locomotion. Interestingly, only environmentally driven, but not self-directed, repetitive behaviors were exacerbated in lesioned mice. Remarkably, in mice with SCIN ablation, the normal pattern of social exploration was replayed continuously. The emerging pattern of social interactions is highly predictable and invariant across time. In vivo electrophysiological recordings indicate that SCIN ablation results in an increase of the functional connectivity between different cortical areas and the motor, but not associative, region of the striatum. Our results identify a role of SCIN in suppressing perseverative behaviors, including socially related ones. In sum, SCIN ablation in mice leads to exacerbated ritualistic-like behaviors that affect social performance, providing a link between SCIN dysfunction and the social impairments present in psychiatric disorders.

Key words: cholinergic interneurons; corticostriatal connectivity; genetic ablation; mice; social behavior; striatum

\section{Significance Statement}

We sought to uncover the impact of striatal cholinergic interneuron (SCIN) degeneration on perseverative behaviors related to obsessive-compulsive disorder (OCD) and Tourette syndrome (TS). We found that extensive SCIN ablation results in exacerbated social interactions, in which normal social contacts were replayed continuously in a highly stereotyped, ritualistic pattern. SCIN ablation also leads to an increase in other spontaneously emitted repetitive behaviors without alteration of motor coordination, balance, or locomotion. Moreover, we identify an increase of functional connectivity between frontal cortical areas and the motor region of the striatum as a putative substrate for the observed behavioral alterations. Therefore, perseveration induced by SCIN ablation extends to social performance as occurs in neuropsychiatric conditions such as OCD and TS.

\section{Introduction}

Rituals, defined as the limitation of behavioral expressions to predictable sequential action streams and repetitive motor patterns (Graybiel, 2008; Lang et al., 2015), constitute part of normal every-

\footnotetext{
Received 0ct. 28, 2016; revised Jan. 23, 2017; accepted Jan. 27, 2017.

Author contributions: Y.V.M., B.Y.B., M.G.M., and J.E.B. designed research; Y.V.M., B.Y.B., and J.P.B. performed research; Y.V.M., B.Y.B., J.P.B., and J.E.B. analyzed data; M.G.M. and J.E.B. wrote the paper.

This work was supported by FONCYT (Grant PICT 2011-0521 and 2013-1523 to M.G.M. and J.E.B.; Grant 20140459 to J.E.B.; and Grant 2015-3687 to M.G.M.), the University of Buenos Aires (Grant UBACYT-2014 to M.G.M.), and the Tourette Association of America (J.E.B. and M.G.M.). We thank Camila Zold and Noelia Weisstaub for critical reading of the manuscript and Cecilia Tubert and Alejandra Prost for providing characterization of ChAT-Cre line.

The authors declare no competing financial interests.

Correspondence should be addressed to Juan E. Belforte, UBA-CONICET, 2155 Paraguay St., 7th Floor, University of Buenos Aires, Buenos Aires 1121, Argentina. E-mail: jbelforte@fmed.uba.ar.

DOI:10.1523/JNEUROSCI.3460-16.2017

Copyright $\odot 2017$ the authors $\quad 0270-6474 / 17 / 372849-10 \$ 15.00 / 0$
}

day life, including social interactions. However, they are considered pathological entities when triggered by unfitting environmental stimuli or result in persistent behaviors that interfere with activities of daily living. Tics, stereotypies, and compulsions, including ritualized behaviors, are core signs of obsessive-compulsive disorder (OCD), Tourette syndrome (TS), and related disorders. Analysis of social behavior in these disorders is often focused on negative reactions of peers such as stigmatization, discrimination, and social exclusion (Eapen et al., 2016). However, alteration of social life in $\mathrm{OCD} / \mathrm{TS}$ and related disorders might depend in part on the dysfunctional social behavior of the patients themselves. A recent study describes a highly heritable subtype of TS characterized by high rates of social disinhibition (Hirschtritt et al., 2016). The putative mechanisms underlying social dysfunction in neuropsychiatric disorders remain largely unknown. 
Common anatomical, genetic, and functional bases have been proposed for OCD and TS (Pauls et al., 1986; Sheppard et al., 1999; Langen et al., 2011), usually involving dysfunctions in the basal ganglia. Corticostriatal synapses, the main input site of information to the basal ganglia, are affected in animal models of OCD and TS, such as in Sapap3- and Slitrk5-deficient mice (Welch et al., 2007; Shmelkov et al., 2010). Remarkably, these mutant mice display compulsive self-grooming and tic-like behaviors, suggesting that aberrant striatal processing of cortical inputs may underlie some aspects of OCD/TS (Gillan et al., 2011; Burguière et al., 2013; Gremel and Costa, 2013; Wan et al., 2014). None of the above-described animal models has been examined for alterations of social behavior. Additional models were developed after the finding that different subpopulations of striatal interneurons are decreased in the brain of patients with TS (Kataoka et al., 2010). In that study, the investigators reported a significant reduction of $\sim 50 \%$ in the density of striatal cholinergic interneurons (SCIN) and also parvalbuminimmunoreactive interneurons in the caudate and putamen of postmortem brains from TS individuals using unbiased stereological methods. Supportive data involving striatal interneurons in TS pathophysiology were obtained when analyzing the striatal transcriptome from patients with TS (Lennington et al., 2016). SCIN are key regulators of striatal function (Apicella, 2007; Pisani et al., 2007) and their partial elimination by immunotoxin treatment in rodents exacerbates pharmacologically induced self-directed repetitive motor patterns (Xu et al., 2015). However, whether SCIN ablation exacerbates spontaneous repetitive behaviors and has an impact on social behavior remains unknown.

Here, we investigated whether the selective elimination of SCIN increases the emission of spontaneous patterns of behavior, turning them more repetitive and predictable. Based on the view that signals emitted by SCIN serve to stop ongoing activity and redirect attention and behavior to new salient stimuli (Ding et al., 2010), we focused on behaviors directed to environmental features and events including social stimuli.

\section{Materials and Methods}

\section{Animals}

All experimental procedures were in accordance with institutional regulations (Institutional Animal Care and Use Committee of the School of Medicine, University of Buenos Aires, ASP\# 21076/15 approval ID: 783/ $15)$ and government regulations (SENASARS617/2002, Argentina). All efforts were made to minimize the number of mice used and their suffering. Mice were maintained on a $12 \mathrm{~h}$ light: $12 \mathrm{~h}$ dark cycle at constant temperature $\left(21-24^{\circ} \mathrm{C}\right)$ with ad libitum access to food and water.

To generate the experimental animals, homozygous choline acetyltransferase (ChAT)-Cre mice (ChAT ${ }^{\mathrm{tm}(\mathrm{cre}) \text { Lowl/J }}$ obtained from Jackson Laboratories, J06410) were crossed with the homozygous iDTR line

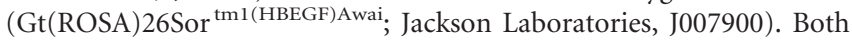
lines are in the C57BL/6 homogeneous background and genotypes were confirmed by PCR. After crossing the ChAT-Cre line with a reporter line (rosa-CAG-LSL-tdTomato-WPRE (Madisen et al., 2010), 99.1\% of the striatal ChAT + cells undergo Cre-mediated recombination (Tomato + ) and $93.6 \%$ of Cre-recombinant cells are ChAT + (data obtained from 2-4 striatal sections from 3-5 mice, C. Tubert, A. Prost, and L. Rela, unpublished data). In addition, we have shown recently that SCIN in the ChAT-Cre line did not electrophysiological differ from SCIN of wildtype mice (Tubert et al., 2016). Offspring hemizygous for the Cre transgene and heterozygous for the loxP-modified allele (ChAT-Cre ${ }^{+/-}$; DTR $^{\text {loxP/wt }}$, hereafter ChAT-DTR) were weaned between 21 and $28 \mathrm{~d}$ of age and group housed in same-sex sibling pairs until stereotactic surgery. The iDTR line allows expression of the Diphtheria toxin (DT) receptor (simian Hbegf) after Cre-mediated recombination of a floxed stop cassette, rendering targeted cells susceptible to the toxin. Selective ablation of SCIN is achieved by stereotaxic microinjection into the striatum as described below.

\section{Stereotaxic procedure}

Adult ChAT-Cre male mice (3-4 months old) were subjected to standard stereotaxic surgery. Briefly, under deep surgical anesthesia (isofluorane $2-1 \%$ ), each mouse was mounted in a stereotaxic frame (Stoelting) with a mouse adaptor and treated with a local anesthetic in the scalp and pressure points (bupivacaine hydrochlorate solution, 5\% w/v, Durocaine, AstraZeneca, 0.1-0.3 ml). Ophthalmic ointment was applied in both eyes to prevent corneal desiccation. DT stocks (Sigma-Aldrich \#D0564) were freshly diluted in sterile saline to a concentration of 200 $\mathrm{pg} / \mu \mathrm{l}$. DT solution (lesion) or saline (sham) were microinjected (at a constant rate of $0.22 \mu \mathrm{l} / \mathrm{min}$ ) unilaterally or bilaterally in dorsal striatum via a 30 gauge stainless steel cannula coupled to a $10 \mu$ l Hamilton syringe driven by a microinfusion pump (Bioanalytical Systems). The injection cannula was left in place for an additional $1 \mathrm{~min}$ before slowly retracting it. DT solution or solvent was injected in three independent sites per hemistriatum: anterior site: $1.3 \mathrm{~mm}$ anterior to bregma, $1.6 \mathrm{~mm}$ lateral and $-2.8 \mathrm{~mm}(0.44 \mu \mathrm{l})$ and $-2.4 \mathrm{~mm}(0.44 \mu \mathrm{l})$ ventral from dura; posterior site: $0.6 \mathrm{~mm}$ anterior to bregma, $1.8 \mathrm{~mm}$ lateral and $-3 \mathrm{~mm}$ ventral from dura $(0.73 \mu \mathrm{l})$ according to the atlas of Paxinos and Franklin (2001). Mice receiving both treatments were housed together in groups of three to five mice per cage until testing. To control for nonspecific effects of DT, a cohort of mice that does not express the DT receptor (ChAT-Cre ${ }^{-l-} ; \mathrm{DTR}^{\text {loxP/loxP }}$ ) were treated as described above with one group receiving $\mathrm{DT}(\mathrm{T}$, toxin) and the other saline ( $\mathrm{S}$, solvent) as a control.

\section{Histology and immunohistochemistry}

At the end of each experiment, all mice received a lethal dose of chloral hydrate $5 \%$ in saline and were perfused transcardially with $10 \mathrm{ml}$ of cold saline solution with $0.04 \%$ heparin (Duncan Laboratories, $5000 \mathrm{UI} / \mathrm{ml}$ ), followed by $40 \mathrm{ml}$ of buffered paraformaldehyde (4\% PFA in $0.1 \mathrm{M} \mathrm{PBS}$ ). Brains were removed, immersed overnight in the same fixative at $4^{\circ} \mathrm{C}$, and then cryoprotected in $30 \%$ sucrose in $0.1 \mathrm{M} \mathrm{PBS}$ at $4^{\circ} \mathrm{C}$ for $24-72 \mathrm{~h}$. Coronal brain sections $(30 \mu \mathrm{m})$ were cut with a sliding microtome equipped with a freezing stage (Leica). The extent of DT-induced SCIN lesion was confirmed by immunohistochemical detection of ChAT in all experimental mice.

Briefly, sections were washed once with PBS, treated with $0.3 \% \mathrm{H}_{2} \mathrm{O}_{2}$ in PBS for $20 \mathrm{~min}, \mathrm{pH} 7.4$, washed for $10 \mathrm{~min}$ in PBS, pH 7.4, and incubated for $2 \mathrm{~h}$ in PBS containing $0.1 \%$ Triton X-100 and 3\% BSA at room temperature. Then, sections were incubated overnight with a goat anti-ChAT primary antibody (1:1000, AB 144P; Millipore) at $4^{\circ} \mathrm{C}$. After PBS washing, sections were incubated with a horse anti-goat biotinylated secondary antibody (1:250, BA-9500; Vector Laboratories) and subsequently with streptavidin-biotin/horseradish peroxidase complex (ABC kit; Vector Laboratories) for $2 \mathrm{~h}$. Immunoreaction was visualized with 3,3'-diaminobenzidine (DAB; Sigma-Aldrich). Immunostaining for parvalbumin, neuropeptide $\mathrm{Y}$, and calretinin markers was performed as described previously (Taravini et al., 2005). For double immunostaining, sections were simultaneously incubated with goat anti-ChAT and mouse anti-parvalbumin primary antibody and sequentially developed with horse anti-goat biotinylated secondary antibody (1:400; Vector Laboratories) plus FITC-conjugated streptoavidin (1:500; Invitrogen) and Cy3-conjugated goat anti-mouse secondary antibody (1:400, 115-165146; Jackson Immunoresearch). Sections were mounted in Vectashield (Vector Laboratories) and images acquired using a FV1000 Fluoview Olympus confocal microscope.

Lesions were assessed by counting ChAT + cell bodies in DAB-stained coronal sections containing dorsal striatum, septum, diagonal band of Brocca, and nucleus accumbens. Sections were photographed and digital files analyzed using the ImageJ cell-counter plugin. All immunoreactive cell bodies with at least one stained process were counted bilaterally in 5 sections per mouse (coronal planes $+1.5,+1.2,+0.86,+0.5,+0.14 \mathrm{~mm}$ from bregma). Cell numbers are referred to as total positive cells per section or integrated as the sum of all counted sections. For unilaterally treated mice, cell numbers are expressed as percentage of untreated side. 
Structures outlines were adopted from the atlas of Paxinos and Franklin (2001).

\section{Behavioral tests}

We subjected bilaterally lesioned and control mice to a behavioral test battery that began 3 weeks after surgery. All behavioral tasks except the $Y$ maze spontaneous alternation task were performed during the light phase by an investigator blinded to genotype/treatment. All sessions were video recorded and mouse position was determined by automatic video tracking (ANY-maze; Stoelting). All mice were moved to a holding room adjacent to the behavioral test room in their home cages at least $1 \mathrm{~h}$ before testing. All findings were confirmed in at least two separate cohorts of mice. All mazes and chambers were thoroughly cleaned with $10 \%$ ethanol, dried between subjects, and sanitized at the end of the day. Only mice in which the lesion reached $75 \%$ compared with control mice were included in the analysis.

Locomotor activity in an open field. Locomotor activity in a novel open field was conducted as described previously (Braz et al., 2015). Briefly, horizontal locomotor activity was assessed in a transparent acrylic openfield arena $(40 \times 40 \mathrm{~cm})$ for $30 \mathrm{~min}$.

Motor coordination test. Balance and motor coordination were assessed by an accelerating rotarod (4-40 rpm over $5 \mathrm{~min}$, Treadmill 7600 for mice, UgoBasile). Each mouse was assessed for 10 trials with $5 \mathrm{~min}$ intertrial intervals.

Grooming and vertical activity. Grooming and vertical activity were assessed in a small acrylic box $(15 \times 20 \mathrm{~cm})$ with a $45^{\circ}$ inclined mirror under the transparent floor for a detailed view of mouse behavior. All sessions lasted $15 \mathrm{~min}$ and were video recorded. Videos were hand scored offline using ANY-maze software. For measuring induced grooming behavior, mice were briefly removed from the mirrored chamber, sprayed with water (misting) from the back of the mouse's body, and returned back to the observation chamber. Spontaneous and induced grooming were assess on 2 separate days. Vertical activity included rearing and wall leaning. Grooming behavior included complete and incomplete sequences of licking, scratching, and washing of the paws, head, and body. Number of events, total time, and event duration were calculated by ANY-maze software.

Marble-burying test. Each mouse was transferred individually into a clean home cage containing 20 dark marbles homogenously distributed over $5 \mathrm{~cm}$ bedding for a $10 \mathrm{~min}$ test. Session was video recorded and buried marbles were counted every 2 min. Numbers and time of digging events and latency to first marble approach were hand scored offline using ANY-maze software.

Hole-board test. Exploratory behavior was assessed in a transparent acrylic hole-board arena $(40 \times 40 \times 40 \mathrm{~cm})$ with 16 equidistant holes $(2$ $\mathrm{cm}$ in diameter) in the floor. Each mouse was placed in the apparatus for $30 \mathrm{~min}$. The number of head-dippings was quantified by hand scoring using ANY-maze.

Elevated plus maze. Anxiety-like behavior was assessed using an elevated plus maze as described previously (Belforte et al., 2010). The maze consisted of 2 open arms $(30 \times 6 \mathrm{~cm})$ with 3 -mm-high ledges and 1 closed arms $(30 \times 6 \mathrm{~cm})$ with $15-\mathrm{cm}$-high opaque walls. The duration of the test was $5 \mathrm{~min}$.

$Y$-maze spontaneous alternation test. This test was conducted as described by Braz et al. (2015). A Y maze with three identical arms of transparent acrylic $(40 \times 4.5 \times 12 \mathrm{~cm}) 120^{\circ}$ apart was used. Experiments were conducted during the initial dark phase (6:00 P.M. to 8:00 P.M.) to maximize exploratory behavior.

Social interaction test. This test was performed on a three-chamber opaque acrylic box, as described previously (Braz et al., 2015). An empty central compartment $(20 \times 20 \mathrm{~cm})$ connects with two lateral compartments $(20 \times 20 \mathrm{~cm})$ containing a wire cup-like container (diameter: 8 $\mathrm{cm}$ ) in which a demonstrator mouse or an object was placed, defining the social compartment and object compartment, respectively. Demonstrators (wild-type 129Sv/Ev male mice 3-5 months old) were habituated extensively to the wire cup containers before usage. Location of demonstrator and object were randomized across trials. One day before testing, experimental mice were habituated to the empty three-chamber box. On the testing day, mice were restricted to the central compartment for 5 min. Then, mice were allowed to freely explore the entire maze for 15 min. Transitions between compartments were detected automatically by overhanging video camera and ANY-maze tracking software. Sniffing behavior directed toward demonstrator/object was hand scored offline and integrated with tracking coordinates obtained from ANY-maze software. Social/object contacts were defined as active sniffing of the experimental subject in a close proximity $(<1 \mathrm{~cm})$ to the circular edge of the wire cup-like container. To analyze the temporal pattern of social interactions, individual perievent histograms were constructed by aligning the time stamps of social contacts to the entrance to the social compartment. Therefore, histograms represent the number of social contacts per visit, in bins of $1 \mathrm{~s}$, from $10 \mathrm{~s}$ before to $30 \mathrm{~s}$ after entrance (time 0 coincides with time of entrance to the social compartment, defined as $80 \%$ of the mouse body crossing from central to social compartment). Total number of social contacts per bin was normalized by the number of the mice visits to the social compartment. Sessions were segmented in 5 min periods and a bin by bin average across mice was used to construct the population histograms depicted in Figure $4 B$. "Social contacts at entrance" was defined as the total number of contacts per visit occurring during the first $5 \mathrm{~s}$ after entrance and "sustained social activity" is the same value for the rest of the visit. To estimate the variability of the social interaction behavior along the session, intraindividual dispersion of social contacts was estimated by the coefficient of variation $(\mathrm{CV} ;=\mathrm{SD} /$ mean $)$ of the social contacts. The CV value was calculated for each mouse in 5 min blocks for the $0-5 \mathrm{~s}$ and $>5 \mathrm{~s}$ epochs defined above using each visit as a sample. The population $\mathrm{CV}$ value for each experimental group was calculated as the mean \pm SEM of individual CV of $n$ mice for the corresponding periods. Predictability of social response was estimated by calculating the probability of social contact at entrance across the session. Probability of social contact was defined as the number of entrances in which the mouse made at least 1 social contact in the first $5 \mathrm{~s}$ over the total number of entrances to the social compartment $(1=$ social contact in all entrances, higher possible predictability over the response).

Social recognition test. The procedures used have been described previously (Belforte et al., 2010). Mice were habituated to a clean novel cage for $1 \mathrm{~h}$ before testing. Testing began when a stimulus mouse was introduced into the cage of each subject for a 1 min confrontation. Wild-type 129Sv/Ev male mice 3-5 months old were used as stimulus mice during the experimental trials. At the end of the 1 min trial, the stimulus mouse was removed and returned to an individual holding cage. This sequence was repeated for four trials with $10 \mathrm{~min}$ intertrial intervals and each stimulus mouse was introduced into the same resident in all four trials. In a fifth "dishabituation" trial, a different stimulus mouse was introduced into the cage of the subject. For the dishabituation trial, the stimulus mouse was picked from a different holding cage than was used for the previous four trials. Sessions were recorded and subsequently scored by trained raters using ANY-maze software. Social investigation included the following: direct contact with the stimulus mouse while inspecting any part of the body surface (including grooming, licking, and pawing); sniffing of the mouth, ears, tail, or ano-genital area; and closely following (within $1 \mathrm{~cm}$ ) the stimulus mouse. Aggressive and sexual behaviors were excluded. To evaluate the reproducibility of the social response, we calculated the intraindividual CV of duration of social contacts across trials. The population $\mathrm{CV}$ value for each experimental group was calculated as the mean \pm SEM of individual CV of $n$ mice.

In vivo electrophysiology. All recordings were performed under urethane anesthesia as described previously (Braz et al., 2015). Briefly, to study striatal responses evoked by cortical stimulation, concentric bipolar electrodes were placed into the prelimbic area of the medial prefrontal cortex and into the motor area M2. Constant current pulses were applied to study corticostriatal synaptic connectivity through multiunitary action potential activity recorded from a three-shank silicon probe consisting of 24 channels placed in the dorsal striatum. To quantify the action potential response, trials were rectified, smoothed, and averaged, allowing the computation of the area of the multiunitary action potential response. 
A

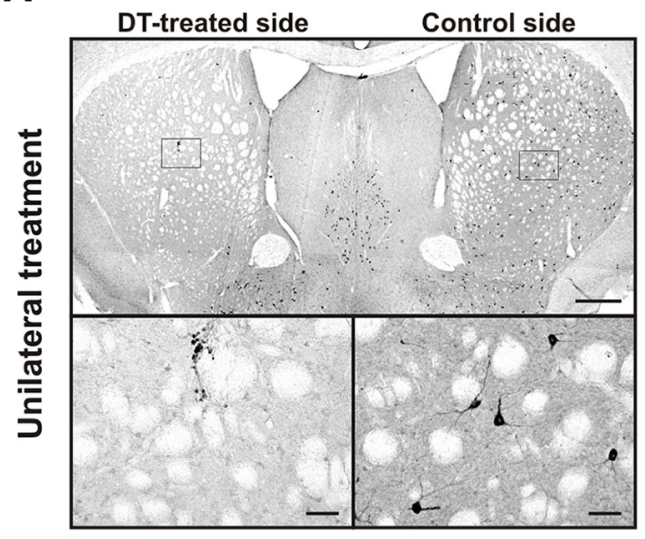

D

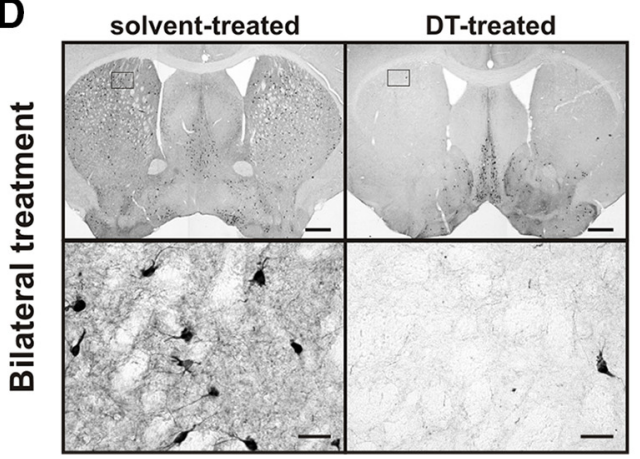

B

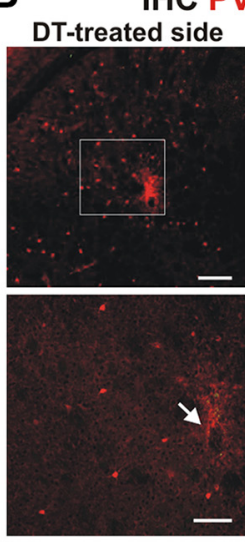

E

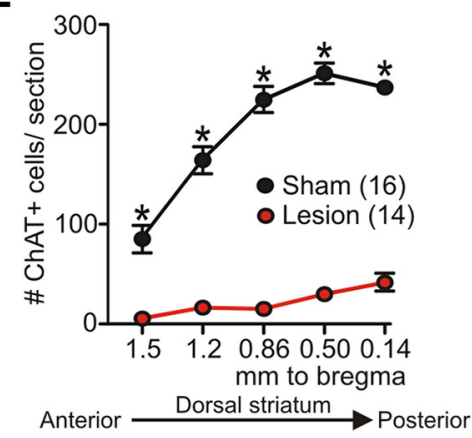

C

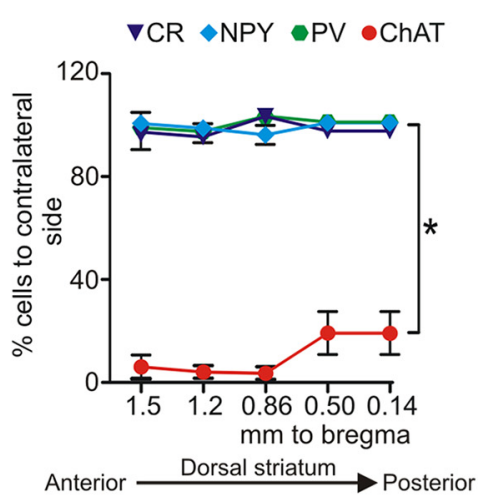

$\mathbf{F}$

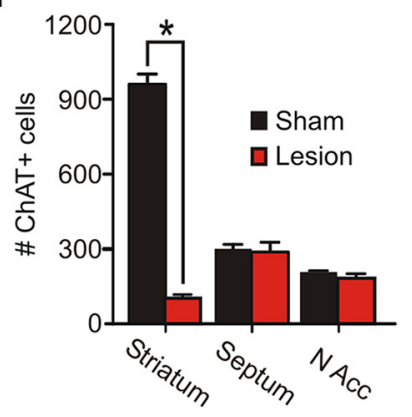

Figure 1. Cell-type-specific and regionally restricted conditional ablation of SCIN in vivo using DT system. $\boldsymbol{A}-\boldsymbol{C}$, Results from unilaterally treated mice. $\boldsymbol{A}$, Representative coronal brain section immunostained against ChAT (DAB) from a unilaterally DT-treated mouse. $\boldsymbol{B}$, Double immunostaining against ChAT (green, SCIN) and parvalbumin (red, PV) in control (right) and DT-treated striatum (left) showing no change in PV-IR cells after SCIN cell degeneration in the vicinity of the striatal microinjection (arrow). C, DT microinjection did not affect the numbers of calretinin (CR), neuropeptide Y (NPY), or parvalbumin (PV) + striatal interneurons, but significantly reduced ChAT + cells $\left({ }^{*} p<0.001 \mathrm{LSD}\right.$ post hoc test vs ChAT, 5 sections per side from 3 mice) along the entire anterior-posterior axe of the striatum. D-F, Post hoc immunohistochemical analysis of bilaterally treated mice subjected to behavioral tests. $\boldsymbol{D}$, Representative coronal brain sections immunostained against ChAT (DAB) from solvent-treated (left) and DT-treated (right) mice depicting the extent of the lesion, high magnifications of boxed areas are shown in the corresponding bottom. $\boldsymbol{E}$, Post hoc verification of SCIN ablation in behaviorally tested mice. A significant decrease was observed in lesioned mice along the entire dorsal striatum $\left({ }^{*} p<0.001 \mathrm{LSD}\right.$ post hoc test, number of mice is indicated in the reference). $\boldsymbol{F}, \mathrm{SCIN}$ bilateral ablation did not reduce (hAT-IR cell number in striatal nearby structures $\left({ }^{*} p<0.001 \mathrm{LSD}\right.$ post hoc test). Scale bars: Iow magnification, $500 \mu \mathrm{m}(\boldsymbol{A}, \boldsymbol{D}), 250 \mu \mathrm{m}(\boldsymbol{B})$; high magnification, $50 \mu \mathrm{m}(\boldsymbol{A}, \boldsymbol{D}), 100 \mu \mathrm{m}(\boldsymbol{B})$.

\section{Statistical analysis}

Data were organized using Microsoft Excel and analyzed using GraphPad Prism software. No datasets violated normality assumptions; 2-tailed parametric statistics were used in all cases and the threshold for significance was set at $p=0.05$. Student's $t$ test or two-way repeated-measures (RM) ANOVA followed by Bonferroni's post hoc test were used, as described in the text and figure legends for each dataset. Significance of probability indexes analyzed by Fisher's exact test corrected for multiple comparisons. Data are presented as mean \pm SEM except when indicated otherwise.

\section{Results}

Cell-type-specific and regionally restricted ablation of SCIN To uncover the impact of SCIN degeneration in the emergence of repetitive behaviors related to OCD and TS, we ablated SCIN selectively using a DT-inducible cell ablation system. To confine the DT receptor (DTR) expression specifically to cholinergic cells, we crossed the ChAT-Cre line (Rossi et al., 2011) with iDTR mice (Buch et al., 2005) to generate the ChAT-DTR line. The ChAT-Cre line drives Cre-recombinase expression selectively to ChAT-expressing cells, including striatal ones, as verified by crossing with reporter lines (Madisen et al., 2010). Therefore, Cre-recombinase-mediated removal of the floxed-stop cassette in cholinergic neurons renders the cells susceptible to the DT. Initially, to characterize the system, ChAT-DTR mice were microinjected unilaterally with DT (322 pg in three sites per side) in the dorsal striatum via stereotaxic surgery. The degree and specificity of DT-induced degeneration was assessed by immunohistochemical staining of striatal sections using different interneuron markers. Two to $3 \mathrm{~d}$ after DT injection, postmortem analysis showed some ChAT + cells with immunohistochemical expression of activated caspase-3 (data not shown). Three weeks after DT injection, massive SCIN loss was observed in the DT-treated side compared with the contralateral control side (Fig. 1A). Lesions spanned the entire anterior-posterior axis of the striatum and comprised $>75 \%$ of total SCIN. Time course analysis using independent groups killed at 2, 3, and 12 weeks after DT injection showed that, after 2 weeks, no further reduction in SCIN number occurred (2 weeks: $8.1 \pm 4.0,3$ weeks: $8.5 \pm 4.6$, and 12 weeks: $2.4 \pm 0.7$ remnant cells as percentage of control side, 5 sections per mouse from 3 mice for each time point ANOVA $p=0.28$ ). The lesions were highly specific for SCIN without any significant reduction in the number of parvalbumin-, calretinin-, or NPY + interneurons in the DT-treated striatum (RM-ANOVA, treatment factor $F_{(3,32)}=176.8, p<0.0001$, ${ }^{\star} p<0.001$ LSD post hoc test vs ChAT; Fig. $\left.1 B, C\right)$. Close examination of microinjection site did not show any appreciable lesion of parvalbumin + interneurons in the region exposed to the highest DT concentration during the injection (Fig. $1 B$ ). To explore the behavioral impact of extensive ablation of SCIN, we injected adult ChAT-DTR male mice bilaterally with DT (lesion) or solvent (sham). Behavioral testing began 3 weeks after surgery and was followed by immunohis- 


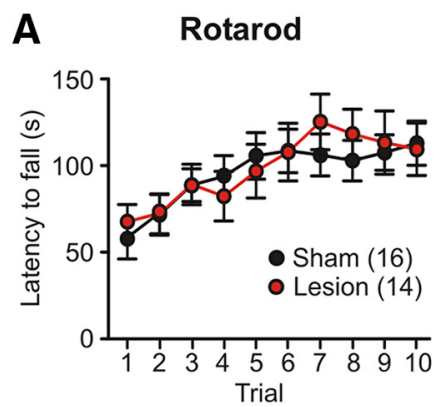

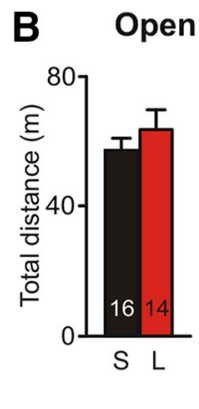
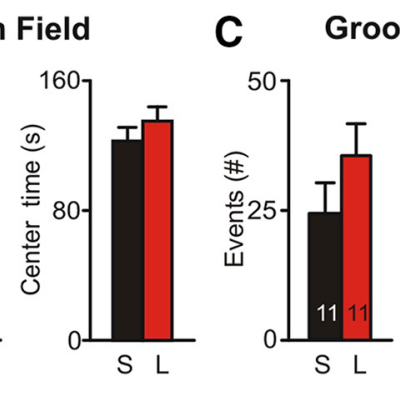

Grooming
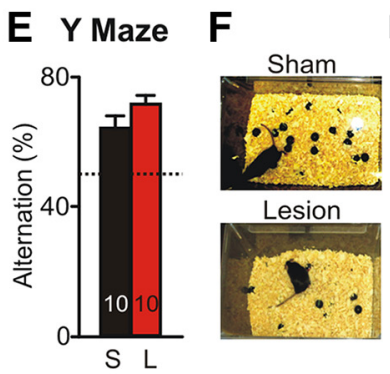

Marble Burying

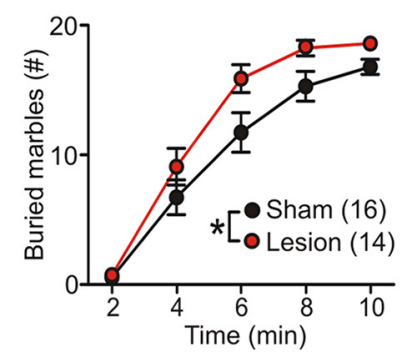

Rearing
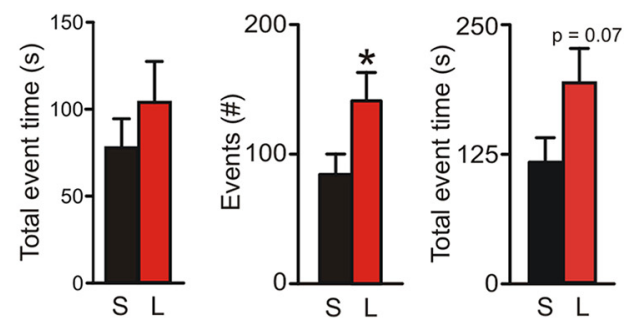

G EPM

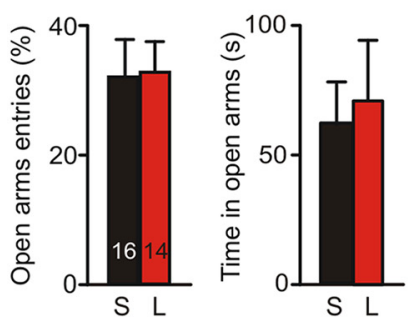

Figure 2. SCIN ablation results in repetitive behaviors. No significant differences were observed in the accelerating rotarod $(\boldsymbol{A})$ or during exploration of a novel open field $(\boldsymbol{B})$. Self-grooming was normal but rearing events were increased $\left(\boldsymbol{C},{ }^{*} p=0.042, t\right.$ test) during exposure to a small enclosure. $\boldsymbol{D}$, Increased repetitive behavior was also observed in the hole-board exploration test ( $t$ test, ${ }^{*} p=0.037$ and 0.048$)$. $\boldsymbol{E}$, Spontaneous alternation in the $Y$ maze showed no deficit in short-term memory ( $t$ test, $\left.p=0.13\right)$. Dotted line illustrates chance levels. $\boldsymbol{F}$, Exacerbated marble-burying behavior exhibited by lesioned mice resembles repetitive behaviors present in $0 C D$ (*treatment factor $p=0.034$ ). Left, Representative photographs at 6 min. $\mathbf{G}$, No anxiety-like phenotype was observed for lesioned mice in the elevated plus maze test. The numbers of mice are indicated in figure references or inside columns.

tochemical verification of lesion extent (RM-ANOVA, $F_{(4,112)}=$ 31.1, $p<0.0001$; Fig. $1 D, E)$. Lesions were restricted to the dorsal striatum without any significant reduction in the number of SCIN $\left(\right.$ RM-ANOVA, interaction $F_{(2,56)}=198.9, p<0.0001$; Fig. $\left.1 F\right)$ and ChAT-immunostained neuropil (data not shown) in nearby structures such as the nucleus accumbens or the septum/diagonal band of Brocca, confirming the anatomical specificity of our manipulation. Only mice with $<25 \%$ of remaining SCIN compared with controls were included in the analysis.

\section{SCIN ablation does not affect basic motor functions}

Because SCIN may regulate motor function (Kaneko et al., 2000), we first evaluated the impact of SCIN lesions on motor performance. Despite extensive SCIN ablation, lesioned mice displayed normal motor coordination and balance in an accelerating rotarod and control levels of locomotor activity during exploration of an unfamiliar open arena (Fig. 2A,B). Tics and stereotyped movements are central for the diagnosis of TS and have been reported in purported animal models of TS (Nordstrom and Burton, 2002; Castellan Baldan et al., 2014). Therefore, we monitored the impact of SCIN lesions on stereotyped behaviors in a small, two-side mirrored enclosure. Inspection of recorded sessions by observers blinded to treatment revealed no obvious orofacial or head-related tics (e.g., head nodding) in lesioned mice. Moreover, lesioned and control mice showed comparable levels of spontaneous grooming (Fig. 2C) and grooming induced by water misting (total grooming time: sham, $221 \pm 40 \mathrm{~s}$; lesion, $185 \pm 27 \mathrm{~s}$; $t$ test $t_{(26)}=0.74, p=0.46, n=14$ mice per group), indicating that the generation of stereotyped self-oriented behaviors was not affected by the lesion. Instead, when analyzing rearing behavior, a repetitive pattern of cage exploration emerged in lesioned mice. Although the number of vertical events was significantly higher in lesioned mice (Fig. 2C), the mean duration of each rearing event was similar across groups (sham, $1.36 \pm 0.08$; lesion, $1.31 \pm 0.11 \mathrm{~s}, t$ test $\left.t_{(20)}=0.33, p=0.74\right)$.

\section{SCIN elimination leads to perseverative-like behaviors}

To extend the study of repetitive behavior, lesioned and control mice were subjected to a hole-board exploration test. Lesioned mice exhibited a marked repetitive exploratory behavior, with a near twofold increase in the number of investigated holes along the entire session (Fig. 2D). This phenotype cannot be a consequence of an inability to remember previously visited holes because lesioned mice displayed control levels of alternation during spontaneous exploration of a Y-maze (Fig. 2E) indicating unaffected short-term memory. Confirmatory results were obtained in a different experimental setting, the marble burying test, which evaluates object-oriented perseveration and has been used extensively to investigate repetitive responses involved in OCD (Thomas et al., 2009). Latency to interact with the first marble was similar between groups ( $\mathrm{sham}, 2.5 \pm 0.4 \mathrm{~s}$; lesion, $2.1 \pm 0.3 \mathrm{~s}$; $t$ test $t_{(28)}=0.91, p=0.37$ ), suggesting a normal exploratory drive. However, lesioned mice buried the marbles significantly faster than control mice (RM-ANOVA, treatment factor $F_{(1,112)}=4.95, p=0.034$; Fig. $\left.2 F\right)$ and exhibited more repetitive digging of cage bedding (number of digging events: sham, $65 \pm 5$, lesion: $86 \pm 7$; $t$ test $t_{(28)}=2.28, p=0.03$ ), signs usually interpreted as compulsive-like behaviors (Shmelkov et al., 2010). The expression of repetitive behaviors may be modified by anxiety; however, the lesioned group showed no signs of anxiety-related behaviors in the open-field or elevated plus maze tests (Fig. $2 B, G)$. These phenotypes cannot result from DT treatment per se because no significant differences were observed in the behavior of solvent and DT-treated mice that do not express the human DT receptor (mice that lack the DTR, i.e., ChAT-Cre ${ }^{-1-}$; $\mathrm{DTR}^{\text {loxP/loxP}}$; Fig. 3 ; open-field: $t$ test $t_{(25)}=1.3, p=0.20$; marble burying: RM-ANOVA treatment factor $F_{(1,92)}=0.18, p=0.67$, interaction $F_{(4,92)}=1.69, p=0.16$; hole board: $t$ test $t_{(19)}=1.45$ $p=0.16$; social interaction test: RM-ANOVA treatment factor $F_{(1,24)}=0.51, p=0.48$, interaction $\left.F_{(1,24)}=0.01, p=0.90\right)$. 
A Open Field

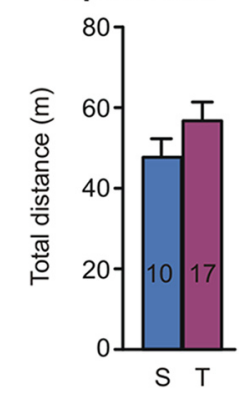

C Hole board

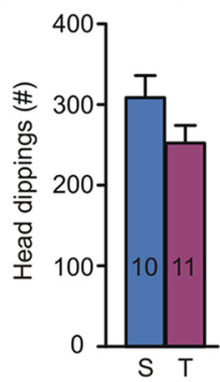

B Marble Burying

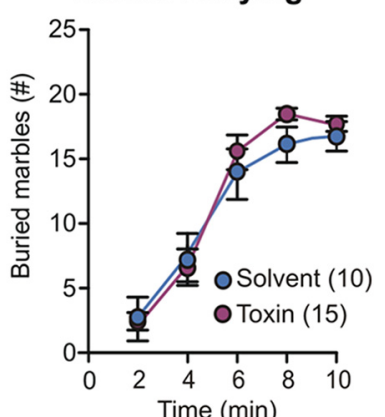

D Social Interaction

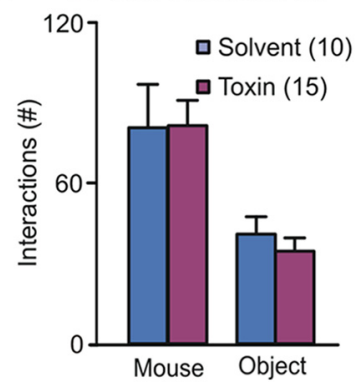

Figure 3. Striatal microinjection of DT produces similar effects than solvent in mice without the DT receptor. To rule out nonspecific effects of DT, a group of mice lacking the DTR (ChAT$\left.\mathrm{Cre}^{-1-} ; \mathrm{DTR}{ }^{\text {loxP/loxP }}\right)$ were bilaterally microinjected in the striatum with the same dose of DT as used in previous experiments with ChAT-Cre+ mice (T, Toxin) or with saline (S, Solvent) as control. No significant differences were observed in exploratory activity in the open field $(\boldsymbol{A}, p=0.98)$, marble-burying $(\boldsymbol{B}, p=0.22$, interaction $p=0.42)$, hole-board $(\boldsymbol{C}, p=0.12)$, or social interaction $(\boldsymbol{D}$, treatment factor $p=0.24$, interaction $p=0.96)$ tests. Numbers of mice used are indicated inside columns or as graph labels in all panels.

Overall, SCIN ablation enhanced behaviors directed to salient environmental features and objects without modifying selfdirected repetitive motor patterns.

\section{Selective elimination of SCIN results in increased ritualistic social exploration}

Diagnosis of OCD, TS, and other psychiatric disorders requires symptom interference with daily functioning, including social activities. To assess whether altered control over repetitive behaviors can affect social life, we tested control and lesioned mice in a three-chamber social interaction task that evaluates the natural tendency of mice to explore a novel conspecific over a novel object (Fig. 4A-E). Latency to the first social approach ( $t$ test $t_{(22)}=0.01, p=0.9$; Fig. $4 D$ ) and average time per social contact (sham, $1.34 \pm 0.17$; lesion, $1.71 \pm 0.18 \mathrm{~s}, t$ test $t_{(22)}=1.29, p=$ 0.21 ) are preserved in lesioned mice, suggesting a normal drive for social exploration. However, the total number of social contacts was significantly increased in lesioned mice (RM-ANOVA, interaction $F_{(1,22)}=7.31, p<0.05$; Fig. $4 A$ ), leading to a significantly higher interaction time (RM-ANOVA, interaction $F_{(1,22)}=5.29, p<0.05$; Fig. $\left.4 B\right)$ without changes in the number of entrances to the social compartment (Fig. $4 C$ ) or in novel object exploration (Fig. 4A,B).

Fine examination of the temporal structure of social behavior showed that, at the beginning of the session, control mice follow a structured pattern of social investigation. While transitioning between compartments, each entrance to the social side results in a social contact within the first seconds, followed by additional contacts timely distributed during the visit (Fig. $5 A, B$ ). Interestingly, this sequence (compartment transition, short-latency social contact, sustained social interactions, exit) became less predictable along the session in control mice (Fig. 5C,D). Instead, lesioned mice continue to display a highly structured pattern of social investigation during the entire session (RM-ANOVA, interaction $F_{(2,44)}=3.27, p<0.05$ and $F_{(2,44)}=3.01, p<0.05$; Fig. $5 C)$. Furthermore, lesioned mice presented significantly lower levels of intraindividual variability of their social responses (RMANOVA, time factor $F_{(2,44)}=7.96, p<0.005$, treatment factor $F_{(1,44)}=4.93, p<0.05, F_{(2,44)}=2.31, p=0.11$, Fig. $5 D$, left; RM-ANOVA, time factor $F_{(2,44)}=8.26, p<0.001$, treatment factor $F_{(1,44)}=5.29, p<0.05, F_{(2,44)}=2.34, p=0.10$, Fig. $5 D$, right), evidencing a higher predictability of their behavior along the session. Coincidentally, lesioned mice maintained the same probability of making a social contact when entering the social compartment along the entire session (probability of social contacts at entrance $0-5 \mathrm{~min}: 0.70 ; 5-10 \mathrm{~min}: 0.83 ; 10-15 \mathrm{~min}: 0.73$; Fisher's exact test $p=0.84)$, whereas control mice showed a decrease in the probability along the task $(0-5$ min: $0.64 ; 5-10$ min: $0.55 ; 10-15$ min: 0.35 ; Fisher's exact test $p<0.05$ ). Interestingly, the social contact probability was similar for both groups at the beginning of the session $(0-5$ min: sham 0.70 , lesion 0.64 ; Fisher's exact test $p=0.49$ ), but differed significantly at the end of the session (10-15 min: sham 0.35, lesion 0.73; Fisher's exact test $p<0.05$ ), supporting the notion that SCIN lesion increase the predictability of the social response. Spatially restricted SCIN ablations, like the ones achieved in previous studies where severe SCIN ablation was obtained in subregions of the striatum, are insufficient to trigger the social perseveration described above (data not shown).

The perseverant social response displayed by SCIN-lesioned mice may arise from a deficit in social memory or social recognition. To explore this possibility, an independent cohort of control and lesioned mice underwent a social recognition task in which test mouse was exposed repeatedly to a conspecific demonstrator in a neutral arena (Fig. 6). As expected, control mice showed intense social exploratory behavior toward the demonstrator during the first $1 \mathrm{~min}$ presentation and, in subsequent trials, spent less time in further investigation, reflecting social shortterm memory (RM-ANOVA time factor $F_{(4,44)}=6.45, p<$ 0.0005). During the last trial, controls again showed a strong interest in a new stimulus mouse, reflecting that the decrease in social interaction in the preceding trials was due to intact formation of social short-term memory. Consistently with a social perseveration phenotype, SCIN-lesioned mice displayed higher interaction times along the entire session (RM-ANOVA treatment factor $F_{(1,44)}=4.5, p=0.057$. Despite the perseverative response displayed, SCIN-lesioned mice habituated their response at the same rate as control mice (RM-ANOVA, treatment $\times$ time interaction $\left.F_{(4,44)}=0.39, p=0.8\right)$, suggesting that social memory was preserved. Furthermore, SCIN lesion did not affect social recognition (Fig. 6, dishabituation trial). Latency to the first social approach was unaffected by SCIN lesion, suggesting normal motivation for social interaction $\left(t\right.$ test $t_{(11)}=0.45$, $p=0.33$; Fig. $6 B$ ). To assess the predictability of social activity, we calculated the coefficient of variation of the intraindividual social response (Fig. 6C). In agreement with the results described above, lesioned mice presented a significantly smaller $\mathrm{CV}$ than did control mice $\left(t\right.$ test, $\left.t_{(11)}=2.47, p<0.05\right)$, confirming that SCIN ablation turns social behavior more structured and perseverative, resembling ritualistic-like behaviors. 
A

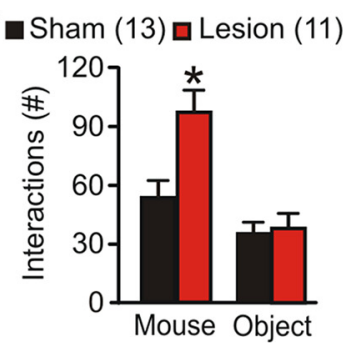

B

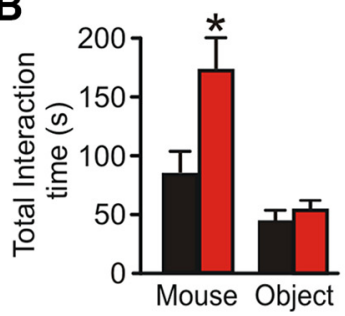

C

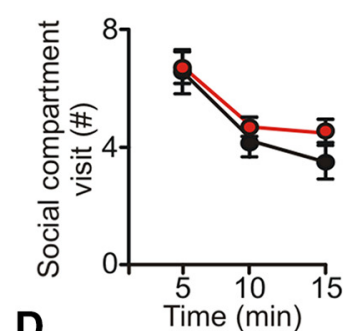

D

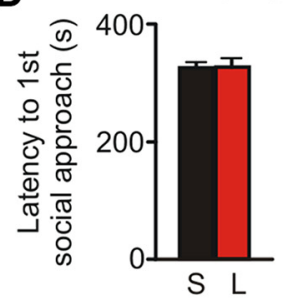

E
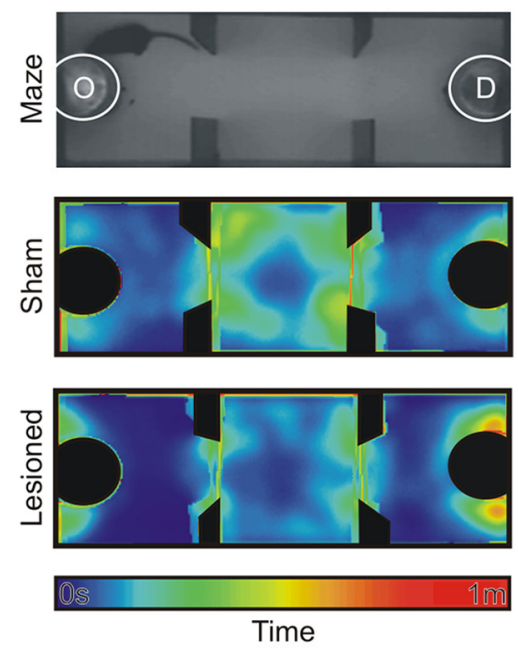

Figure 4. Selective elimination of SCIN leads to increased social exploration. Three-compartment social interaction test is shown. $A, B$, SCIN-lesioned mice showed higher levels of social interaction directed toward an unfamiliar mouse but normal exploration of a novel object $\left({ }^{*} p<0.05\right.$, Bonferroni post hoc test). $C$, Number of entries to the chamber hosting the social stimuli along the 15 min session depicting normal environmental exploration by lesioned mice. $\boldsymbol{D}$, Latency to the first social contact does not differ between lesioned and control mice $(p=0.9)$. $\boldsymbol{E}$, Top, Upright view of the behavioral setup: the three-compartment maze is shown with an subject mice exploring the object chamber (0) located in the opposite compartment than the demonstrator (D). Average heat maps for time spent by subject mice during the entire session are shown. The population heat map was constructed based on head position. Middle, Control group. Bottom, Lesioned group.

A

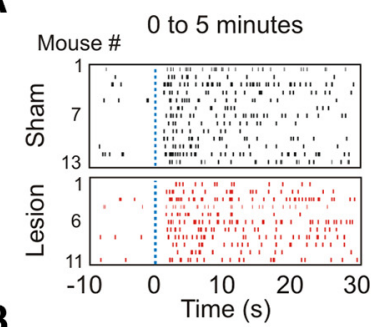

B

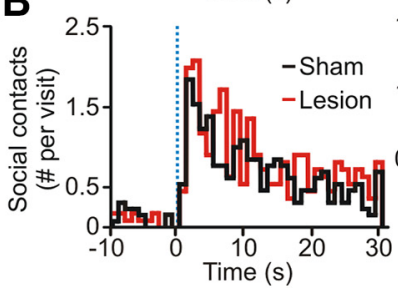

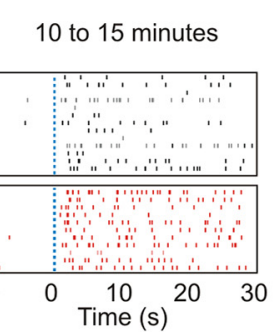

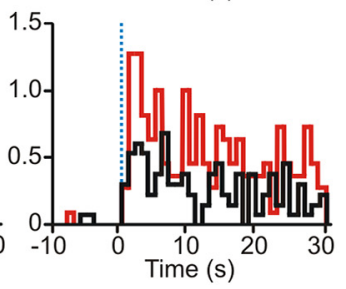

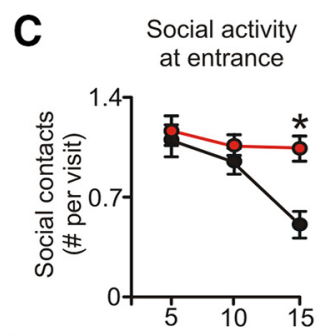

Sustained social activity

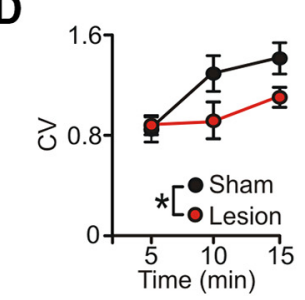

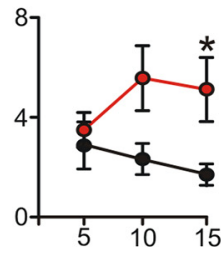

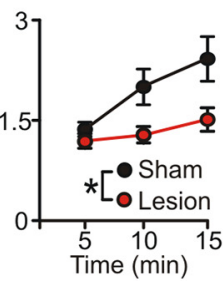

Figure 5. Social interaction in SCIN-lesioned mice follows a highly structured and invariant pattern. $\boldsymbol{A}$, Raster plot representing the time course of social contacts at the beginning (left) and at the end (right) of the session. Each row represents all social contacts (red and black event marks) made by a single mouse aligned to the entrance to the social compartment (blue dotted line, time 0 ) during the corresponding session period. Each event mark represents one social contact. $B$, Perievent-histograms of social contacts for each experimental group aligned to the entrance to the social compartment for the same session periods as in top panel. $C$, Time course of social interactions occurring early after entrance $(0-5 \mathrm{~s}$ from social compartment entrance, left) or during the rest of the visit (right). Lesioned mice exhibit a persistent pattern of social exploration along the session significantly different from control mice. ( ${ }^{2} L S D$ posthoc test, $\left.p<0.05\right)$. D, Control mice show an increase in the variability of their response toward the social stimuli along the session, as evidenced by an increase in the intraindividual CV. Instead, lesioned mice persist in the initial structured pattern of social interactions exhibiting significantly lower intraindividual CV than control mice at the end of the session (*treatment factor $p<0.05$ ).

\section{Cortical drive to striatal motor territory increases after SCIN ablation}

Corticostriatal circuitry dysfunction has been implicated in repetitive/compulsive behaviors in animal models of OCD and related disorders (Shmelkov et al., 2010; Wan et al., 2014). Accordingly, to elucidate the functional consequences of the SCIN ablation on corticostriatal connectivity, we have conducted in vivo electrophysiological recordings assessing the impact of SCIN ablation in segregation of cortical inputs across striatal territories. We have used this experimental approach successfully to characterize alterations in corticostriatal functional connectivity induced by chronic dopaminergic depletion in mice (Galiñanes et al., 2011; Braz et al., 2015). The striatal responses evoked by pre- limbic and motor cortices stimulation were recorded using a multiple contact silicon probe array spanning dorsal striatum (Fig. 7A-C). Higher evoked responses after prelimbic stimulation were obtained in medial regions, whereas motor cortex stimulation induced marked responses in lateral regions of the striatum as described previously (Braz et al., 2015). However, discernible responses were obtained along the entire medial-lateral axis of the striatum for both cortices, reflecting the existence of partially overlapping channels for processing cortical information in the striatum (Fig. 7D). SCIN ablation did not affect the corticostriatal connectivity over the medial region, but strengthened the evoked responses measured after cortical stimulation in the lateral one (RM-ANOVA, lesion factor: $F_{(1,22)}=7.77, p<0.02$; interaction: 
A
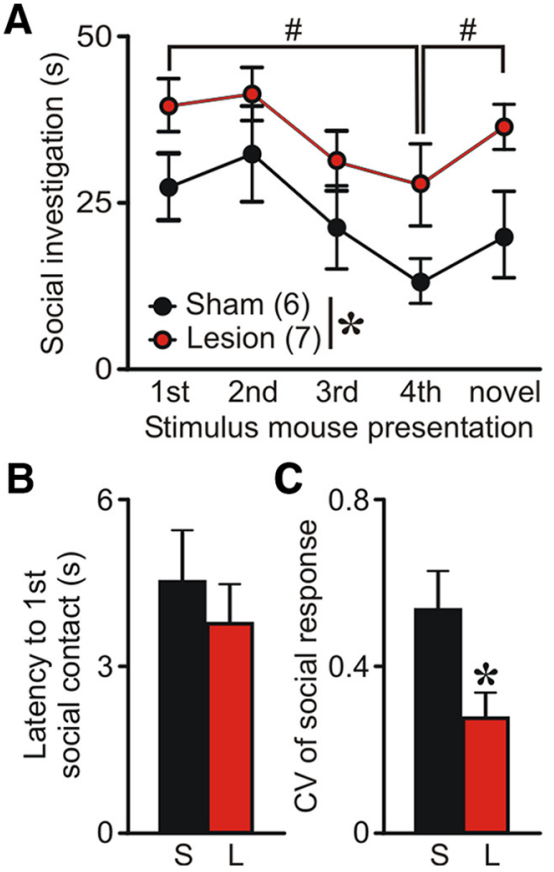

Figure 6. Social memory and recognition are preserved in SCIN-lesioned mice. The socialrecognition test revealed a perseverative social behavior for lesioned mice, with increased social interactions structured in a more predictable pattern. $\boldsymbol{A}$, Control mice decreased social investigation time after repeated exposures (1 min each) to a stimulus mouse. A fifth dishabituation trial elicited an increased response to a novel mouse, showing individual recognition. Similarly, lesioned mice showed habituation after repeated presentations of the stimulus mouse $\left(^{*} p=\right.$ $0.057, \# p<0.05$, LSD post hoc test), indicating normal social memory. In addition, lesioned and control mice did not differ in their capacity for recognizing a novel conspecific mouse (\# $p<$ 0.05 vs novel). Instead, lesioned mice exhibited increased social investigation during the entire session regardless of the familiarity with the demonstrator. $\boldsymbol{B}$, Latency to the first social contact does not differ between lesioned and control mice $(p=0.33)$. C, Duration of social contacts during the five presentations of the task was more predictable for lesioned mice than for controls $\left({ }^{*} p<0.05\right)$.

$F_{(1,22)}=3.06, p=0.11$; Fig. $\left.7 D\right)$. These results indicate that SCIN ablation results in an increase of the functional connectivity between different cortical areas and the motor region, but not the associative region, of the striatum, suggesting that cortical inputs may over-recruit striatal regions involved in triggering and selecting motor responses, resulting in abnormal repetition of otherwise adaptive behavioral responses.

\section{Discussion}

Here, we have characterized a new transgenic mouse model in which inducible ablation of SCIN is achieved with high efficiency combined with unprecedented cell-type and region specificities. Using this model, we have provided evidence that SCIN ablation leads to an increase in repetitive behaviors without alteration of motor coordination, balance, or locomotion. Our experiments allowed us to dissect self-directed repetitive behaviors from object-directed ones, suggesting a previously ignored role of SCIN in the control of environmentally driven motor sequences. Moreover, previous studies ablating SCIN have reported the emergence of motor stereotypies only after pharmacological induction with dopaminergic agents (Kaneko et al., 2000; Xu et al., 2015). However, in our model with extended SCIN ablation, ritualistic-like behaviors emerged spontaneously in novel contexts (that can act as a mild stressor), as occurs in OCD and TS patients.

\section{Role of SCIN in the control of social behavior}

We have described, for the first time to the best of our knowledge, an impact of SCIN dysfunction on social behavior. The sustained social activity displayed by lesioned mice, emerging in the form of a highly structured sequence of repetitive reexploration of the already investigated mice, resembles some aspects of altered social life of neuropsychiatric patients, such as the exacerbated need for reassurance displayed by some OCD patients (Starcevic et al., 2012) and the high rates of social disinhibition observed in highly heritable forms of TS (Hirschtritt et al., 2016). This perseverative social behavior may be the result of an impaired capacity of the basal ganglia to select an alternative routine after environmental stimuli lose novelty. For instance, in a novel environment where a congener is present, an initial highly stereotyped investigative phase takes place. After a certain level of information is acquired, exploratory drive is directed to other environmental stimuli, leading to a more disperse interaction with the social stimulus. We speculate that SCIN may control the normal switch between different behavioral states by signaling the relative novelty/salience of environmental cues along the session, as proposed by Ding et al. (2010). In this vein, it has been proposed that TANs encode changes in previously learned instrumental contingencies (Apicella et al., 1991; Stalnaker et al., 2016) that may represent "state prediction error signals" promoting the exploration of alternative actions in changing environments (Bradfield et al., 2013). Here, we propose a more extended function of SCIN, with the cholinergic signals exerting an online control over behavioral states by upgrading the threshold for action selection in the striatum continuously in response to changes in environmental saliencies and the information acquired through exploration.

\section{SCIN ablation as a bottom-up model to study psychiatric disorders}

TS patients show a $>50 \%$ reduction of SCIN in both the associative and sensorimotor regions of the striatum, but SCIN are preserved in the limbic striatum of patients (Kataoka et al., 2010). Therefore, our animal model reproduces more closely the SCIN pathology observed in TS patients than previous studies inducing SCIN lesions in restricted areas of the dorsal striatum. However, postmortem studies have shown additional changes in the brains of TS patients, including a diminution of the number of other populations of striatal interneurons (Kataoka et al., 2010; Lennington et al., 2016), which are not reproduced in our model. Moreover, in our model, SCIN ablation was performed when mice were 3 months old (i.e., adults), better resembling the onset age for OCD ( $\sim 20$ years) than TS (3-8 years) and may be a factor contributing to the absence of tic-related phenotypes in our system; however, TS may persist into adulthood as was the case in the patients used in the postmortem studies discussed above (Kataoka et al., 2010; Lennington et al., 2016). However, our aim was not to validate a new animal model of TS, but rather to provide a bottom-up perspective of the consequences of SCIN dysfunction consistent with new frameworks for the study of mental disorders, such as the Research Domain Criteria (RDoC) project, by providing a causal link between a well defined pathophysiological entity (SCIN dysfunction) and the emergence of symptoms (ritualistic-like behaviors on social performance) regardless of the clinical entity with which they may be connected.

\section{Cholinergic and dopaminergic signals control self-directed behaviors and stereotypies}

Previous studies have failed to show exacerbated emission of spontaneous repetitive behaviors or social dysfunction after 
A
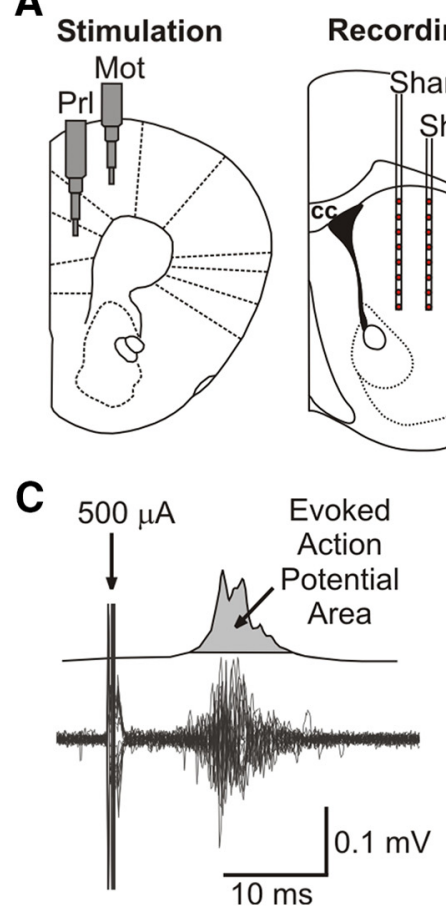

B
Recording

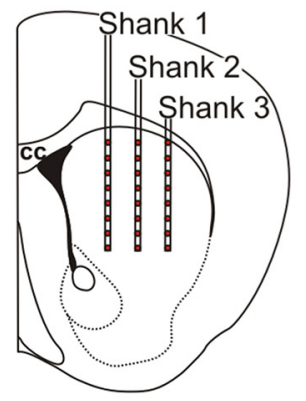

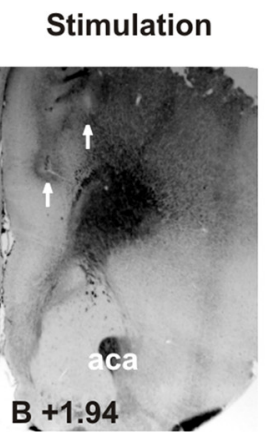

\section{Recording}

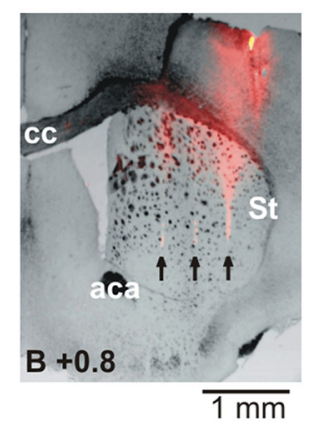

घham (6) 口Lesion (5-6)

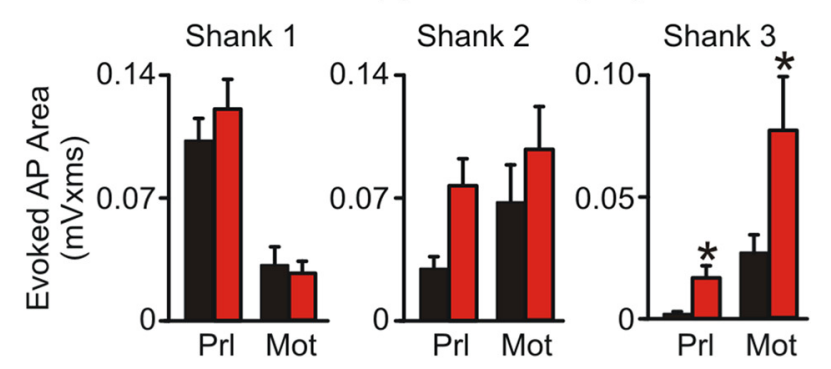

Figure 7. SCIN ablation results in increased cortical drive of the motor territory of the striatum. $\boldsymbol{A}$, Concentric bipolar electrodes used for electric stimulation were aimed to $\mathrm{mPFC}$ (prelimbic region PRL) and motor (Mot) cortices. A multiple contact silicon probe array with 3 shanks spanning dorsal striatum was used to record evoked responses across the medial-lateral regions (shank 1-3 from associative to motor territories of the striatum) from 5-6 SCIN-lesioned and 6 control mice under urethane anesthesia in vivo. B, Representative histological sections showing the location of cortical stimulation (left) and striatal recording (right) electrodes (aca: anterior commissure; St, striatum; cc: corpus callosum). C, To quantify striatal action potential responses, individual trials (bottom) were rectified, smoothed, and averaged, allowing the computation of the area of the multiunitary action potential response (top). D. Multiunitary action potential response evoked in medial (shank 1 ) to lateral striatum (shank 3 ) after stimulation (500 $\mu \mathrm{A}$ ) of $\mathrm{mPFC}$ (Prl) and motor (Mot) cortices in SCIN-ablated and control mice. No significant effect of ablation was observed in associative regions; however, cortical inputs to motor territory (shank 3) were significantly potentiated in lesioned mice. ${ }^{*} p<0.05$. Data are shown as mean $\pm \mathrm{SEM}$; mouse numbers are indicated in parentheses.

SCIN ablation, as we report in the present study (Xu et al., 2015). The lesions obtained by Xu et al. (2015) encompassed a limited region of the dorsolateral striatum with an almost complete SCIN depletion in the core area, rather than a widespread depletion of SCIN across most of the dorsal striatum. This may provide an explanation for the absence of any spontaneous behavioral abnormality related to OCD or TS in their model. However, they found increased motor stereotypies after strong acoustic stimulation (stress-induced stereotypies) or pharmacological treatment (amphetamine-induced stereotypies) in animals with lesions restricted to the dorsolateral motor region of the striatum. Considering that severe stereotypies have been reported in mice with increased VChAT expression only after amphetamine treatment (Crittenden et al., 2014), the appearance of abnormal selfdirected stereotypies may require dopamine receptor activation, most likely D1 receptor, together with an unbalanced cholinergic tone. In addition, several studies have shown "tic-like" motor activity after injection of GABA-A receptor antagonists into the motor striatum, which did not require concomitant pharmacological stimulation of dopamine receptors (McCairn et al., 2009; Bronfeld et al., 2013). More recently, selective ablation of striatal fast spiking interneurons (FSIs), which constitute one of the more important sources of local inhibition, resulted in exacerbate grooming after acute stress ( $\mathrm{Xu}$ et al., 2016). It has also been reported that a reduction of the number of striatal FSIs contributes to the intense spontaneous grooming observed in the Sapap-3 mutant mouse (Burguière et al., 2013). FSIs, which are more abundant in the dorsolateral sensorimotor striatum than in the medial "associative" dorsal striatum (Gerfen et al., 1985), are partially depleted from the brains of patients with TS (Kalanithi et al., 2005; Kataoka et al., 2010). Therefore, depletion of FSIs from the motor striatum, in conjunction with dopamine receptor stimulation, may result in exacerbation of self-directed repetitive motor patterns, but the emergence of more complex repetitive behaviors directed to environmental events including social stimuli may only appear after extended SCIN dysfunction also involving the medial striatum.

Overall, our findings show that SCIN degeneration can lead to the emergence of perseverative behaviors oriented to salient environmental stimuli, resembling ritualistic-like behaviors observed in adult OCD and TS patients. Self-oriented perseveration, also observed in these syndromes, may respond to other pathophysiological mechanisms, probably related to striatal FSIs and dopamine D1 receptor overactivation (McCairn et al., 2009; Worbe et al., 2013). Conspecifics are particularly effective in triggering ritualistic social interactions in animals with SCIN ablation, suggesting a mechanism through which a reduced number of SCIN could interfere with normal social life in different psychiatric disorders.

\section{References}

Apicella P (2007) Leading tonically active neurons of the striatum from reward detection to context recognition. Trends Neurosci 30:299-306. CrossRef Medline

Apicella P, Scarnati E, Schultz W (1991) Tonically discharging neurons of monkey striatum respond to preparatory and rewarding stimuli. Exp Brain Res 84:672-675. Medline

Belforte JE, Zsiros V, Sklar ER, Jiang Z, Yu G, Li Y, Quinlan EM, Nakazawa K (2010) Postnatal NMDA receptor ablation in corticolimbic interneurons confers schizophrenia-like phenotypes. Nat Neurosci 13:76-83. CrossRef Medline

Bradfield LA, Bertran-Gonzalez J, Chieng B, Balleine BW (2013) The 
thalamostriatal pathway and cholinergic control of goal-directed action: interlacing new with existing learning in the striatum. Neuron 79:153166. CrossRef Medline

Braz BY, Galiñanes GL, Taravini IR, Belforte JE, Murer MG (2015) Altered corticostriatal connectivity and exploration/exploitation imbalance emerge as intermediate phenotypes for a neonatal dopamine dysfunction. Neuropsychopharmacology 40:2576-2587. CrossRef Medline

Bronfeld M, Yael D, Belelovsky K, Bar-Gad I (2013) Motor tics evoked by striatal disinhibition in the rat. Front Syst Neurosci 7:50. CrossRef Medline

Buch T, Heppner FL, Tertilt C, Heinen TJ, Kremer M, Wunderlich FT, Jung S, Waisman A (2005) A Cre-inducible diphtheria toxin receptor mediates cell lineage ablation after toxin administration. Nat Methods 2:419-426. CrossRef Medline

Burguière E, Monteiro P, Feng G, Graybiel AM (2013) Optogenetic stimulation of lateral orbitofronto-striatal pathway suppresses compulsive behaviors. Science 340:1243-1246. CrossRef Medline

Castellan Baldan L et al. (2014) Histidine decarboxylase deficiency causes tourette syndrome: parallel findings in humans and mice. Neuron 81:7790. CrossRef Medline

Crittenden JR, Lacey CJ, Lee T, Bowden HA, Graybiel AM (2014) Severe drug-induced repetitive behaviors and striatal overexpression of VAChT in ChAT-ChR2-EYFP BAC transgenic mice. Front Neural Circuits 8:57. CrossRef Medline

Ding JB, Guzman JN, Peterson JD, Goldberg JA, Surmeier DJ (2010) Thalamic gating of corticostriatal signaling by cholinergic interneurons. Neuron 67:294-307. CrossRef Medline

Eapen V, Cavanna AE, Robertson MM (2016) Comorbidities, social impact, and quality of life in Tourette syndrome. Front Psychiatry 7:97. CrossRef Medline

Galiñanes GL, Braz BY, Murer MG (2011) Origin and properties of striatal local field potential responses to cortical stimulation: temporal regulation by fast inhibitory connections. PLoS One 6:e28473. CrossRef Medline

Gerfen CR, Baimbridge KG, Miller JJ (1985) The neostriatal mosaic: compartmental distribution of calcium-binding protein and parvalbumin in the basal ganglia of the rat and monkey. Proc Natl Acad Sci U S A 82: 8780-8784. CrossRef Medline

Gillan CM, Papmeyer M, Morein-Zamir S, Sahakian BJ, Fineberg NA, Robbins TW, de Wit S (2011) Disruption in the balance between goaldirected behavior and habit learning in obsessive-compulsive disorder. Am J Psychiatry 168:718-726. CrossRef Medline

Graybiel AM (2008) Habits, rituals, and the evaluative brain. Annu Rev Neurosci 31:359-387. CrossRef Medline

Gremel CM, Costa RM (2013) Orbitofrontal and striatal circuits dynamically encode the shift between goal-directed and habitual actions. Nat Commun 4:2264. CrossRef Medline

Hirschtritt ME et al. (2016) Social disinhibition is a heritable subphenotype of tics in Tourette syndrome. Neurology 87:497-504. CrossRef Medline

Kalanithi PS, Zheng W, Kataoka Y, DiFiglia M, Grantz H, Saper CB, Schwartz ML, Leckman JF, Vaccarino FM (2005) Altered parvalbumin-positive neuron distribution in basal ganglia of individuals with Tourette syndrome. Proc Natl Acad Sci U S A 102:13307-13312. CrossRef Medline

Kaneko S, Hikida T, Watanabe D, Ichinose H, Nagatsu T, Kreitman RJ, Pastan I, Nakanishi S (2000) Synaptic integration mediated by striatal cholinergic interneurons in basal ganglia function. Science 289:633-637. CrossRef Medline

Kataoka Y, Kalanithi PS, Grantz H, Schwartz ML, Saper C, Leckman JF, Vaccarino FM (2010) Decreased number of parvalbumin and cholinergic interneurons in the striatum of individuals with Tourette syndrome. J Comp Neurol 518:277-291. CrossRef Medline

Lang M, Krátký J, Shaver JH, Jerotijević D, Xygalatas D (2015) Effects of anxiety on spontaneous ritualized behavior. Curr Biol 25:1892-1897. CrossRef Medline

Langen M, Durston S, Kas MJ, van Engeland H, Staal WG (2011) The neurobiology of repetitive behavior: ... and men. Neurosci Biobehav Rev 35: 356-365. CrossRef Medline

Lennington JB, Coppola G, Kataoka-Sasaki Y, Fernandez TV, Palejev D, Li Y, Huttner A, Pletikos M, Sestan N, Leckman JF, Vaccarino FM (2016) Transcriptome analysis of the human striatum in Tourette syndrome. Biol Psychiatry 79:372-382. CrossRef Medline

Madisen L, Zwingman TA, Sunkin SM, Oh SW, Zariwala HA, Gu H, Ng LL,
Palmiter RD, Hawrylycz MJ, Jones AR, Lein ES, Zeng H (2010) A robust and high-throughput Cre reporting and characterization system for the whole mouse brain. Nat Neurosci 13:133-140. CrossRef Medline

McCairn KW, Bronfeld M, Belelovsky K, Bar-Gad I (2009) The neurophysiological correlates of motor tics following focal striatal disinhibition. Brain 132:2125-2138. CrossRef Medline

Nordstrom EJ, Burton FH (2002) A transgenic model of comorbid Tourette's syndrome and obsessive-compulsive disorder circuitry. Mol Psychiatry 7:617-625, 524. Medline

Pauls DL, Towbin KE, Leckman JF, Zahner GE, Cohen DJ (1986) Gilles de la Tourette's syndrome and obsessive-compulsive disorder. Arch Gen Psychiatry 43:1180-1182. CrossRef Medline

Paxinos G, Franklin KBF (2001) The mouse brain in stereotaxic coordinates, Ed 2. San Diego: Academic.

Pisani A, Bernardi G, Ding J, Surmeier DJ (2007) Re-emergence of striatal cholinergic interneurons in movement disorders. Trends Neurosci 30: 545-553. CrossRef Medline

Rossi J, Balthasar N, Olson D, Scott M, Berglund E, Lee CE, Choi MJ, Lauzon D, Lowell BB, Elmquist JK (2011) Melanocortin-4 receptors expressed by cholinergic neurons regulate energy balance and glucose homeostasis. Cell Metab 13:195-204. CrossRef Medline

Sheppard DM, Bradshaw JL, Purcell R, Pantelis C (1999) Tourette's and comorbid syndromes Obsessive compulsive and attention deficit hyperactivity disorder: a common etiology? Clin Psychol Rev 19:531-552. CrossRef Medline

Shmelkov SV, Hormigo A, Jing D, Proenca CC, Bath KG, Milde T, Shmelkov E, Kushner JS, Baljevic M, Dincheva I, Murphy AJ, Valenzuela DM, Gale NW, Yancopoulos GD, Ninan I, Lee FS, Rafii S (2010) Slitrk5 deficiency impairs corticostriatal circuitry and leads to obsessive-compulsive-like behaviors in mice. Nat Med 16:598-602, 1p following 602. CrossRef Medline

Stalnaker TA, Berg B, Aujla N, Schoenbaum G (2016) Cholinergic interneurons use orbitofrontal input to track beliefs about current state. J Neurosci 36:6242-6257. CrossRef Medline

Starcevic V, Berle D, Brakoulias V, Sammut P, Moses K, Milicevic D, Hannan A (2012) Interpersonal reassurance seeking in obsessive-compulsive disorder and its relationship with checking compulsions. Psychiatry Res 200:560-567. CrossRef Medline

Taravini IR, Ferrario JE, Delbe J, Ginestet L, Debeir T, Courty J, Murer MG, Gershanik OS, Raisman-Vozari R (2005) Immunodetection of heparinbinding growth associated molecule (pleiotrophin) in striatal interneurons. Brain Res 1066:196-200. CrossRef Medline

Thomas A, Burant A, Bui N, Graham D, Yuva-Paylor LA, Paylor R (2009) Marble burying reflects a repetitive and perseverative behavior more than novelty-induced anxiety. Psychopharmacology (Berl) 204:361-373. CrossRef Medline

Tubert C, Taravini IR, Flores-Barrera E, Sánchez GM, Prost MA, Avale ME, Tseng KY, Rela L, Murer MG (2016) Decrease of a current mediated by Kv1.3 channels causes striatal cholinergic interneuron hyperexcitability in experimental Parkinsonism. Cell Rep 16:2749-2762. CrossRef Medline

Wan Y, Ade KK, Caffall Z, Ilcim Ozlu M, Eroglu C, Feng G, Calakos N (2014) Circuit-selective striatal synaptic dysfunction in the Sapap3 knockout mouse model of obsessive-compulsive disorder. Biol Psychiatry 75:623630. CrossRef Medline

Welch JM, Lu J, Rodriguiz RM, Trotta NC, Peca J, Ding JD, Feliciano C, Chen M, Adams JP, Luo J, Dudek SM, Weinberg RJ, Calakos N, Wetsel WC, Feng G (2007) Cortico-striatal synaptic defects and OCD-like behaviours in Sapap3-mutant mice. Nature 448:894-900. CrossRef Medline

Worbe Y, Sgambato-Faure V, Epinat J, Chaigneau M, Tandé D, François C, Féger J, Tremblay L (2013) Towards a primate model of Gilles de la Tourette syndrome: anatomo-behavioural correlation of disorders induced by striatal dysfunction. Cortex 49:1126-1140. CrossRef Medline

Xu M, Kobets A, Du JC, Lennington J, Li L, Banasr M, Duman RS, Vaccarino FM, DiLeone RJ, Pittenger C (2015) Targeted ablation of cholinergic interneurons in the dorsolateral striatum produces behavioral manifestations of Tourette syndrome. Proc Natl Acad Sci U S A 112:893-898. CrossRef Medline

Xu M, Li L, Pittenger C (2016) Ablation of fast-spiking interneurons in the dorsal striatum, recapitulating abnormalities seen post-mortem in Tourette syndrome, produces anxiety and elevated grooming. Neuroscience 324:321-329. CrossRef Medline 